\title{
Evaluation of an Ophthalmology Session for Third-Year Medical Students at the University of Colorado School of Medicine
}

\author{
Judas Z. Kelley, BA ${ }^{1}$ Jasleen K. Singh, MD² \\ ${ }^{1}$ University of Colorado School of Medicine, Aurora, Colorado \\ ${ }^{2}$ Department of Ophthalmology, University of Colorado School of \\ Medicine, Children's Hospital Colorado, Aurora, Colorado \\ Journal of Academic Ophthalmology 2018;10:e23-e31.
}

\begin{abstract}
Address for correspondence Jasleen K. Singh, MD, Department of Ophthalmology, University of Colorado School of Medicine, Children's Hospital Colorado, 13123 East 16th Avenue, Box B430, Aurora, CO 80045 (e-mail: jasleen.singh@ucdenver.edu).
\end{abstract}

\begin{abstract}
Keywords

- medical student education

- program evaluation

- new curriculum

Background Medical school ophthalmology education continues to be marginalized, creating the challenge of teaching students how to adequately diagnose and manage common ocular diseases in a limited time.

Objective This study aimed to improve the ophthalmic medical knowledge and clinical skills of third-year medical students.

Methods This curriculum was provided to 76 out of 124 third-year medical students in the 2016 class at the University of Colorado-Denver School of Medicine program. It was a half-day session that incorporated lectures, problem-based cases, and clinical skills. Participating students were given a self-reflection survey on their knowledge at the beginning and end of the session. Participating students were given a pre-test and post-test 6 months later via SurveyMonkey. Another quiz was given to all students within the class. Comparisons of pre- and post-tests, pre- and post-surveys, and quiz results in the participating and nonparticipating groups were made.

Results Participating students' mean pre-test score was $61.8 \%(n=76)$ and post-test score was $72.3 \%(n=47), p<0.01$, indicating a significant increase in knowledge. There was an increase in 2 points on the Likert scale of understanding in ophthalmology between surveys. Participating students received a quiz mean score of $61.2 \%$, which was significantly higher than those in the nonparticipating group (54.3\%), $p<0.05$. Conclusion This session improved medical students' confidence and medical knowledge in ophthalmology.
\end{abstract}

Ophthalmology education in North American medical schools has declined significantly over the last few decades. The Association of University Professors of Ophthalmology (AUPO) has conducted several surveys of medical institutions to evaluate the state of ophthalmic education provided to medical students. The last survey conducted showed a steady decline from $68 \%$ in 2000 to $30 \%$ in 2004 in the prevalence of required ophthalmology rotations in medical schools. ${ }^{1}$ Currently, the Liaison Committee on Medical Education does not have specific guidelines for ophthalmology

received

June 5,2017

accepted after revision

January 8, 2018
DOI https://doi.org/

10.1055/s-0038-1631880. ISSN 2475-4757. training; however, the United States Medical Licensing Examination does include ophthalmic content. ${ }^{1}$ Primary care physicians should have some background knowledge in ophthalmic diseases and ocular manifestations of systemic diseases. Cataracts, glaucoma, macular degeneration, and diabetic retinopathy are the leading causes of agerelated diseases in the United States.

With the decreasing exposure to ophthalmology during medical school and primary care residency curriculums, these physicians are inadequately trained in the initial
Copyright $\odot 2018$ by Thieme Medical Publishers, Inc., 333 Seventh Avenue, New York, NY 10001, USA. Tel: +1(212) 584-4662.
License terms

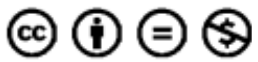


management of eye-related diseases. A survey of residency program directors from primary care-related fields (internal medicine, family medicine, and pediatrics) suggested that medical schools were not adequately preparing incoming residents with ophthalmic education. ${ }^{2}$ Even though program directors felt that ophthalmic education was important, more than $85 \%$ of programs responded that a major component of this education should occur in medical school. ${ }^{3} \mathrm{~A}$ survey of family medicine program directors evaluating skills expected of incoming residents compared with the residents' self-reports of ability to perform that skill also showed this disconnect in ophthalmic education. Although $56 \%$ of program directors felt incoming residents should be able to perform a fluorescein eye exam, only $34 \%$ of residents felt comfortable with this skill. ${ }^{4}$ Therefore, there is a great need for innovative courses and resources for medical students to improve their knowledge and comfort with ophthalmic content and skills to improve their future success as physicians across medical specialties. In an era of an increased recognition of the importance of primary care medicine, it is clear that comfort with basic ophthalmic disease concepts and examination techniques is fundamental to the training of medical students.

The aim of this program evaluation was to evaluate a new course in the ophthalmology curriculum required for thirdyear medical students. This course was a required half-day session with a single ophthalmologist that combined minilectures, case-based learning, and clinical skills training. We hypothesized that this half-day session in a small group format would improve a third-year medical student's medical knowledge and confidence with diagnosis, treatment, and skills specific to ophthalmology.

\section{Methods}

A new curriculum in ophthalmology was designed for thirdyear medical students of the class of 2016 at the University of Colorado School of Medicine during their surgery clinical rotation. These half-day sessions were mandatory for all third-year students starting half way through the academic year. Therefore, approximately half of the class participated in this course. This program evaluation was approved by the Colorado Institutional Review Board as a program evaluation.

\section{Program Curriculum}

The course was composed of mini-lectures, clinical skills, and problem-based learning in the format of cases with class sizes ranging from four to seven students. The topics of the curriculum were based on the AUPO Task Force guidelines for medical student education ( - Table $\mathbf{1}) .^{5}$ The three main areas of competency were core skills, the recognition of red flag physical findings, and knowledge base. The core skills were focused on physical exam skills necessary for a competent generalist physician to complete a screening eye examination. The red flag physical findings area focused on signs and symptoms that should be recognized by a generalist physician as appropriate for a prompt consult with ophthalmology, as they were potentially sight or life threatening. The knowledge base area was identified as a minimum base of ophthalmic knowledge appropriate for medical students.

Each half-day course was instructed by the same faculty member of the Department of Ophthalmology, University of Colorado, which helped to limit the resources required for implementation. The course schedule alternated between mini-lectures, clinical skills, and problem-based learning cases with specific topics outlined in the course schedule (-Table 2 ).

\section{Program Evaluation}

All students in the medical student class of 2016 were separated into either the participating group or nonparticipating group based on whether or not they attended one of the half-day sessions. There was a 15-multiple choice question (MCQ) pre-test given to every student in the participating group at the beginning of the session (Appendix 1) to assess their medical knowledge in ophthalmology. Every student in the participating group was also given a 13-question pre-survey using a Likert scale to evaluate their own confidence in ophthalmology education (Appendix 2). At the conclusion of the session, the students were given a 13-question post-survey (similar to the pre-survey) on how they felt the session affected their ophthalmic knowledge using a Likert scale. The 13th question was a free text question for students to give constructive feedback on the course (Appendix 3). At the end of the students' third year, the participating group was given the same 15-MCQ test as a post-test via SurveyMonkey to assess their retainment of ophthalmology medical knowledge. Furthermore, all students in the class, including both the participating group and nonparticipating group, were given a shorter sevenquestion quiz at the end of the year (Appendix 4). The scores on these tests and quizzes were not used as part of the formal grading of the students. All students who participated in this course were informed that their scores and participation had no impact on their formal surgery grade evaluation.

\section{Analysis}

The pre- and post-survey results in the participating group were compared. The mean pre- and post-test scores were also compared in the participating group using Student's $t$-test. The seven-question quiz mean scores of the participating group were compared with the nonparticipating group. Simple Student's $t$-tests were used to determine significance, which was set at $p<0.05$.

\section{Results}

There were 124 students in total in the medical student class of 2016 . Seventy-six (61.3\%) of those students were in the participating group, while 48 (38.7\%) of the students were in the nonparticipating group.

The pre-survey contained three unique questions gauging students' confidence in ophthalmology and its emphasis in medical school. The mean score for time dedicated to ophthalmology in medical school being sufficient was low at 1.72 with a standard deviation (SD) of 0.66. Student's interest in learning more about ophthalmology had a higher 
Table 1 AUPO MedEd Task Force core knowledge and skills competencies

\begin{tabular}{|c|c|c|}
\hline Core skills & Recognition of red flag physical findings & Knowledge basis \\
\hline $\begin{array}{l}\text { 8-point physical examination: } \\
\text { - Visual acuity: properly record near } \\
\text { card and pinhole } \\
\text { - Pupil assessment } \\
\text { - Alignment assessment (Hirshberg) } \\
\text { - Extraocular muscle ductions } \\
\text { - Confrontation visual fields } \\
\text { - Penlight assessment of lids, conjunc- } \\
\text { tiva/sclera, cornea } \\
\text { - Anterior chamber depth estimation } \\
\text { - Assessment of clarity of media } \\
\text { - Funduscopy } \\
\text { - Disc (cup, color, contour, margins, } \\
\text { vessels) } \\
\text { - Retina in adults/cooperative children } \\
\text { - Red reflex in infants/children } \\
\text { - Instillation of drops } \\
\text { - Lid eversion } \\
\text { - Removal of superficial foreign bodies } \\
\text { - Conjunctiva } \\
\text { - Cornea } \\
\text { - Ocular irrigation }\end{array}$ & $\begin{array}{l}\text { - Orbit: cellulitis (septal/preseptal); } \\
\text { proptosis } \\
\text { - Extraocular muscles: 3rd, 4th, 6th } \\
\text { nerve palsies; gross mal-alignment; } \\
\text { amblyopia } \\
\text { - Globes: gross rupture (or possibility of } \\
\text { same) } \\
\text { - Pupils: relative afferent pupillary } \\
\text { defect, anisocoria, light/near disso- } \\
\text { ciation, leukocoria } \\
\text { - Confrontation visual fields: gross } \\
\text { defects } \\
\text { - Lids: ptosis, lid lag/stare, swelling, } \\
\text { masses } \\
\text { - Conjunctiva: tarsal/forniceal foreign } \\
\text { body, hemorrhage, severe hyper- } \\
\text { purulent conjunctivitis (gonococcal), } \\
\text { or conjunctivitis with lymphadeno- } \\
\text { pathy (epidemic kerato-conjunctivi- } \\
\text { tis) } \\
\text { - Cornea: abrasions, infectious ulcers } \\
\text { (bacterial or viral), foreign body } \\
\text { - Anterior chamber: shallow chamber, } \\
\text { angle closure } \\
\text { - Fundus: normal anatomy vs. abnormal } \\
\text { (using elements in column 1), disc } \\
\text { edema } \\
\text { - Hollenhorst plaque, glaucomatous } \\
\text { cupping, macular degenerative } \\
\text { changes }\end{array}$ & 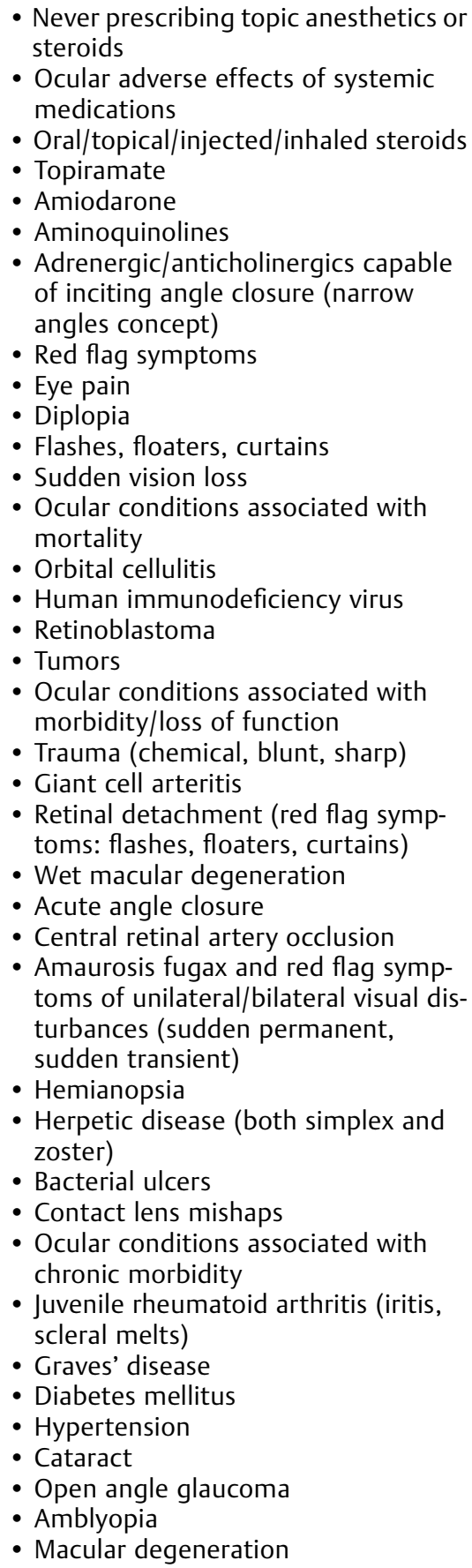 \\
\hline
\end{tabular}

Abbreviation: AUPO, the Association of University Professors of Ophthalmology.

Source: Adapted from Mottow-Lippa. ${ }^{5}$

mean score of 3.77 ( $S D=0.72$ ). Student's interest in pursuing ophthalmology had a slightly lower mean score of 2.15 with greater variability ( $S D=1.04$ ).

The pre- and post-survey responses from the participating group were compared in the topics of general comfort with ophthalmology, ocular anatomy, ocular history, basic eye exam, anterior segment diseases, optic nerve diseases, retina diseases, strabismus, and lid lesions, and whether more ophthalmology exposure would be helpful in medical school using a Likert scale (-Fig. 1). The post-survey showed an overall improvement in confidence in each aspect of ophthalmology that was covered in the session. Students still felt that more exposure to ophthalmology would be beneficial even after completion of the course. 
Table 2 Medical student ophthalmology course schedule

\begin{tabular}{|l|l|}
\hline Session & Objectives \\
\hline Pre-test and survey & Record baseline knowledge and confidence \\
\hline Basic anatomy and terms & Ocular anatomy \\
\hline Practical: eye exam Part 1 & Visual acuity, tension (tonopen), pupils, confrontational visual fields \\
\hline Ocular pharmacology & $\begin{array}{l}\text { Topical anesthetics, dilation drops, pilocarpine, topical antibiotics, topical } \\
\text { steroids, glaucoma meds (topical and oral) }\end{array}$ \\
\hline Practical: eye exam Part 2 & Instilling eye drops, irrigation, everting lids, eye shield \\
\hline Anterior segment basics (case based) & Conjunctivitis, corneal abrasion, corneal ulcer, open globe, cataracts, glaucoma \\
\hline Practical: eye exam Part 3 & Penlight examination, slit lamp examination \\
\hline Anterior segment surgery & Cataract extraction \\
\hline Break & \multicolumn{2}{|l}{$\begin{array}{l}\text { Optic neuropathy, giant cell arteritis, central retinal artery occlusion, hyper- } \\
\text { tension retinopathy, diabetic retinopathy, age-related macular degeneration, } \\
\text { retinal detachment }\end{array}$} \\
\hline Posterior segment basics (case based) & Direct ophthalmoscopy \\
\hline Practical: eye exam Part 4 & $\begin{array}{l}\text { Strabismus, esotropia, exotropia, cranial nerve palsies, amblyopia, ptosis, } \\
\text { preseptal/orbital cellulitis, thyroid eye disease, eyelid lesions }\end{array}$ \\
\hline Pediatrics and plastics & Motility, external \\
\hline Practical: eye exam Part 5 & Review pre-test \\
\hline Post-survey &
\end{tabular}

The post-survey included two questions specifically designed to analyze the course and instructor. Students rated the effectiveness of the instructor very highly with a mean score of $4.95(\mathrm{SD}=0.22)$. Students also rated the time dedicated to the session being sufficient highly with a mean score of 4.43 (SD $=0.76)$.

The final question of the post-survey was a free response question asking for critique: what students liked and what could be improved. There were many common themes among the students' free responses. Students felt that the session was interactive and engaging, and they enjoyed the hands-on aspects of the session. Students wished they had this session earlier in their medical school career. Students felt that the session was long and commented on breaking up the session to more than one half-day. Students also would have liked interacting with real patients in a clinic setting. Many students

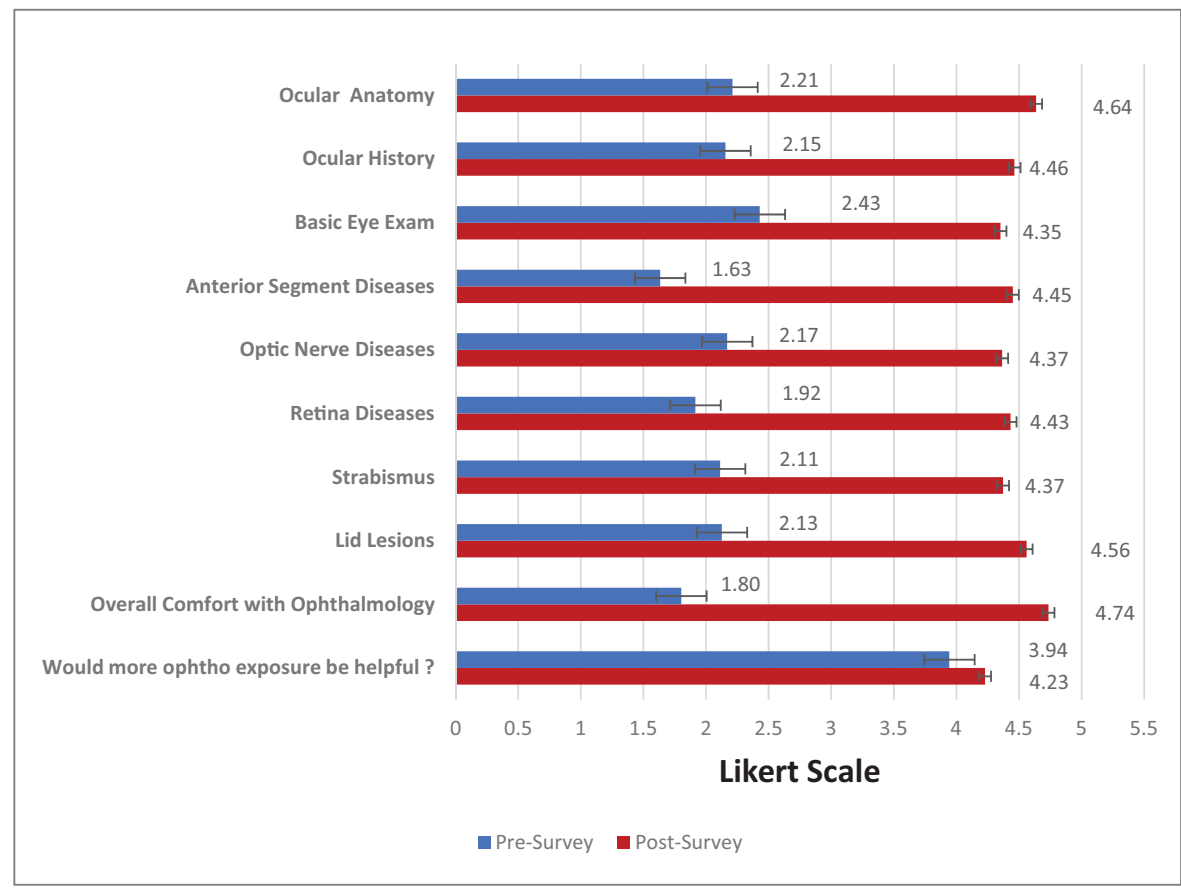

Fig. 1 Comparison of pre- and post-survey responses of the participating group. 
commented on appreciating the style and enthusiasm of the instructor and the "high-yield emphasis" of the course.

Students in the participating group had a pre-test response rate of $100 \%$ and answered $61.8 \%$ of the questions correctly on the pre-test. There was a much lower response rate of $61.8 \%$ for students in the participating group who took the post-test via SurveyMonkey. However, the average score of the post-test was $72.3 \%$ correct, which showed an improvement in score after participating in the course ( $p<0.001$; - Table 3$)$.

Students in the participating group had a quiz response rate of $96.1 \%$, which was comparable to the quiz response rate of the students in the nonparticipating group, $95.8 \%$. The participating group had a mean quiz score of $61.2 \%$, which was higher than their classmates in the nonparticipating group with a mean score of $54.3 \%(p=0.028$; - Table 4$)$.

\section{Discussion}

Increasing ophthalmology exposure to medical students has become a difficult task with the marginalization of this subspecialty from the curriculum. Exposure to ophthalmology during medical school may be all the education most medical professionals receive during their careers unless they choose to go into the field. This fundamental knowledge of ophthalmology remains vital, as many of the visually debilitating diseases (diabetic retinopathy, glaucoma, macular degeneration, etc.) or initial presentations of common eye problems (conjunctivitis, corneal abrasion, etc.) may present to the primary care provider first.

Results from the pre-survey-specific questions highlighted that most students who participated in the course were not interested in pursuing a career in ophthalmology. This was in line with previous literature where approximately $98 \%$ of students graduating medical school do not pursue a career in ophthalmology. ${ }^{6}$ However, students at the University of Colorado-Denver remained interested in learning more about ophthalmology and felt that the amount of

Table 3 Comparison of response rates and pre- and post-test \% correct in the participating group

\begin{tabular}{|l|l|l|l|}
\hline Type of test & $\begin{array}{l}\text { Response } \\
\text { rate (\%) }\end{array}$ & $\%$ Correct & $p$-Value \\
\hline Pre-test & 100 & 61.8 & $<0.001$ \\
\hline Post-test & 61.8 & 72.3 & \\
\hline
\end{tabular}

Table 4 Comparison of response rates and quiz \% correct between the participating and nonparticipating groups

\begin{tabular}{|l|l|l|l|}
\hline Student group & $\begin{array}{l}\text { Response } \\
\text { rate (\%) }\end{array}$ & \% Correct & $p$-Value \\
\hline Participating & 96.1 & 61.2 & 0.028 \\
\hline Nonparticipating & 95.8 & 54.3 & \\
\hline
\end{tabular}

time dedicated to ophthalmology in medical school was insufficient. These results highlight that medical students at this university recognize most of them will not go into the field, but many of them will still need baseline knowledge of diagnosis and treatment for basic ophthalmic diseases. This decline in necessary ophthalmology knowledge is not only something noticed by residency directors in their incoming interns, but is also recognized by our students' own assessments of their knowledge gaps during their first clinical year of medical school.

Students commented on many of the strengths of the course in their free responses and assessment of the instructor in the post-survey. Some of the free responses also commented on enjoying the engaging and interactivity of the instructor and the case-based learning. Students felt that the course was taught with an emphasis on practical knowledge and skills that were "high-yield" for medical students and primary care providers. Students also enjoyed being able to participate in the hands-on aspects of the course in a small group manner that re-emphasized the purpose of the skill.

Students also offered insight into ways the course could be improved. Many felt that the ophthalmology session should have taken place earlier in the medical student curriculum, so they could utilize these skills during other rotations such as neurology, family medicine, or emergency medicine. Students also wanted to decrease the time spent in the lecture room and add clinic time where they could work with patients. Some students commented on the length of the session being long and suggested having the course duration over more than one half day to increase retention and decrease the volume of knowledge presented in a short time.

Participation in the ophthalmology course significantly improved student's confidence in ophthalmology. Students showed improved comfort with all aspects of ophthalmology that were presented including ocular anatomy, ocular history, the basic eye exam, anterior segment diseases, optic nerve diseases, retina diseases, strabismus, and lid lesions. Nearly every topic had at least a 2-point increase in confidence in the post-survey. This supports the success of one of the main objectives of the ophthalmology session: to increase medical student's confidence in diagnosis, treatment, and skills unique to ophthalmology.

Students in the participating group had an increase in mean test score after this ophthalmology session, and an increased mean quiz score compared with their peers in the nonparticipating group. The scores within the participating group were comparable to the results of similar small group, problem and case-based learning courses at the University of Wisconsin School of Medicine (mean pre-test score of 55\% and post-test score of $89 \%$ ) and Penn State College of Medicine (mean pre-test score of $55 \%$ and post-test score of $80 \%) .{ }^{6,7}$ These results support the ability of this course to improve the understanding of common ophthalmology content among third-year medical students by increasing their medical knowledge.

This course evaluation does have some limitations. The students were not all taught at the same time during the academic year; therefore, the timing of the course during the 
third year may have affected the results of the post-test and quiz. Second, this course evaluation did not take into consideration that students may have had a variety of exposures to ophthalmology prior to taking this session, such as research interests, shadowing, etc.

While our evaluation was able to assess the knowledge and attitudes of the students at the University of ColoradoDenver, there was no direct assessment of an improvement in physical exam skills of our participating students. The students were provided with the opportunity to practice their basic eye exam skills with guidance, and our evaluation gathered how they felt about their own skills before and after the session. Another limitation is the lower response rate of the post-test, which may have influenced the interpretation of the post-test results. This was given to students in an optional SurveyMonkey format, and the response rate was less than the other surveys and quizzes. An overall limitation is the extensive time spent preparing and teaching the course by one attending physician, which limits its sustainability. While our course has limitations, the students who had the opportunity to participate in the course did show an overall improvement in their knowledge of ophthalmology as well as an improvement of their comfort of ophthalmology. While the students in the nonparticipating group did not have the opportunity to access the material presented in this course due to the nature of the third-year clerkship curriculum design, this course is now required by our School of Medicine for every student during their surgery clerkship based on the data of this course evaluation.

It is imperative that ophthalmology departments develop unique methods to teach medical students about eye disease and management to fit within their school's curriculum. At the University of Colorado School of Medicine, this half-day ophthalmology session for third-year students during their surgery rotation was successful and filled a gap in the current curriculum. The main objectives of the course, increasing student's comfort and knowledge in diagnosis, treatment, and skills unique to ophthalmology, were achieved.
Future improvements for course organization will focus on incorporating other faculty and teaching methodologies. This will decrease the length of the session, retain the same breadth of information, and will help make this course more sustainable and effective.

\section{Conflict of Interest}

None declared.

\section{Funding}

Funding was provided by the University of Colorado School of Medicine Enhancing Education Grant.

\section{Note}

This program evaluation was also presented as a poster at the Association of University Professors in Ophthalmology Meeting in Ft. Lauderdale, Florida, on January 29, 2016.

\section{References}

1 Quillen DA, Harper RA, Haik BG. Medical student education in ophthalmology: crisis and opportunity. Ophthalmology 2005; 112(11):1867-1868

2 Shah M, Knoch D, Waxman E. The state of ophthalmology medical student education in the United States and Canada, 2012 through 2013. Ophthalmology 2014;121(06):1160-1163

3 Stern GA; The Association of University Professors of Ophthalmology Education Committee. Teaching ophthalmology to primary care physicians. Arch Ophthalmol 1995;113(06):722-724

4 Dickson GM, Chesser AK, Woods NK, Krug NR, Kellerman RD. Family medicine residency program director expectations of procedural skills of medical school graduates. Fam Med 2013;45(06):392-399

5 Mottow-Lippa L. Ophthalmology in the medical school curriculum: reestablishing our value and effecting change. Ophthalmology 2009;116(07):1235-1236, 1236.e1

6 Quillen DA, Cantore WA. Impact of a 1-day ophthalmology experience on medical students. Ophthalmology 2006;113(12): 2307-2309

7 Farrell TA, Albanese MA, Pomrehn PR Jr. Problem-based learning in ophthalmology: a pilot program for curricular renewal. Arch Ophthalmol 1999;117(09):1223-1226 


\section{Appendix 1: Test}

\section{MS3 Ophthalmology Test}

1. Which extraocular muscle is not included in the conal space behind the eye?

a. Inferior oblique.

b. Lateral rectus.

c. Superior rectus.

d. Superior oblique.

e. Inferior rectus.

2. Which of the following is a potential risk of giving a retrobulbar block for anesthesia?
a. Retrobulbar hemorrhage.
b. Intrathecal block.
c. Loss of vision.
d. All of the above.
e. $A$ and $B$.

3. What is the antidote to atropine toxicity?
a. Tropicamide.
b. Physostigmine.
c. Metoprolol.
d. Acetaminophen.
e. Pilocarpine.

4. Which antiglaucoma medication do you not want to give a patient with a history of sickle-cell disease?
a. Timolol.
b. Brimonidine.
c. Latanoprost.
d. Mannitol.
e. Acetazolamide.

5. The following are all complications of steroid use except:
a. Cataracts.
b. Retinal detachment.
c. Glaucoma.
d. Hyperglycemia.
e. Personality changes.

6. Which medication can induce idiopathic intracranial hypertension?
a. Tetracycline.
b. Amoxicillin.
c. Topiramate.
d. Viagra.
e. Digoxin.

7. An 8-year-old presents with pain, redness, and foreign body sensation in his right eye that started this morning. You note the following findings, what is your diagnosis?

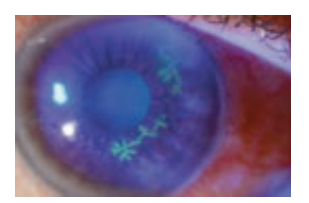
a. Corneal abrasion.
b. Dry eye.
c. Corneal ulcer.
d. HSV keratitis.
e. Corneal foreign body.

8. Angle closure glaucoma has all of the following symptoms except?
a. Headache.
b. Blurry vision.
c. Discharge.
d. Eye redness.
e. Nausea and vomiting.

9. All of the following can result in permanent vision loss except?
a. DM retinopathy.
b. HTN retinopathy.
c. Cataracts.
d. Angle closure glaucoma.
e. Age-related macular degeneration.

10. A patient presents to you with being punched in the right eye. He now has flashes, floaters, and feels like a curtain or shade is over his vision. His vision is $20 / 80$. What is the most likely diagnosis?
a. Optic neuropathy.
b. Corneal abrasion.
c. Hyphema.
d. Retinal detachment from a retinal break.
e. Vitreous hemorrhage.

11. A 23-year-old man presents to you with new-onset diplopia. You note the following finding. What is your next step?

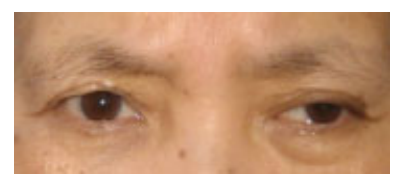
a. Measure his deviation.
b. Prism glasses.
c. Strabismus surgery.
d. Neuroimaging.
e. Observation.

12. A 10-year-old female presents to your office with swelling of her left eye. Her skin is tender to touch. She can barely open her eye, but when she can there is pain with eye movement. She also notes blurry vision. What is your next step?
a. Oral antibiotics.
b. Admit for IV antibiotics.
c. Order a CT of the head and orbits.
d. B and C.
e. All of the above.

13. A 35-year-old man has a new bump on his upper eyelid. It started $\sim 2$ days ago, and is now tender to touch. You note the following finding on exam. How would you treat this lesion first?

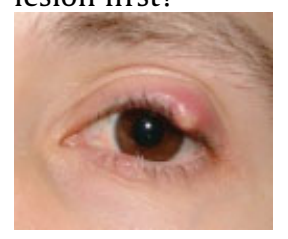



a. Erythromycin ointment.
b. Warm compresses.
c. Surgical incision and drainage.
d. CT scan of the orbit.
e. Ultrasound.

14. Cataracts can be caused by all of the following diseases except:
a. Congenital syphilis.
b. Down's syndrome.
c. Rubella.
d. CMV.
e. Hyperlipidemia.

\section{Appendix 2: Pre-survey}

\section{MS3 Ophthalmology Pre-survey}

Scale:

1-strongly disagree, 2-disagree, 3-neutral, 4-agree, 5strongly agree.

1. Overall, how comfortable do you feel with ophthalmology?

$1,2,3,4,5$.

2. Do you feel you understand ocular anatomy?

$1,2,3,4,5$.

3. Do you feel comfortable in performing an ocular history? $1,2,3,4,5$.

4. Do you feel confident in performing a basic eye exam? $1,2,3,4,5$.

5. Do you feel that you have a good understanding of anterior segment diseases?

$1,2,3,4,5$.

6. Do you feel that you have a good understanding of optic nerve diseases?

$1,2,3,4,5$.

7. Do you feel that you have a good understanding of retinal diseases?

$1,2,3,4,5$.

8. Do you feel that you have a good understanding of strabismus?

$1,2,3,4,5$.

9. Do you feel that you have a good understanding of basic lid lesions?

$1,2,3,4,5$.

10. Do you feel that the amount of time dedicated to ophthalmology so far in medical school is sufficient?

$1,2,3,4,5$.

11. Do you feel that more ophthalmology exposure would be helpful while you are in medical school?

1, 2, 3, 4, 5 .

12. Are you interested in learning more about ophthalmology?

$1,2,3,4,5$.

13. Are you interested in pursuing ophthalmology?

$1,2,3,4,5$.
15. A 30-year-old man presents to the emergency department with sudden pain and vision loss after a bottle was thrown at his eye. You take a quick look given his level of cooperation and have a high suspicion for an open globe injury. You should do all of the following except:

a. Check a vision.

b. Check a pressure to see if the eye is soft.

c. Place an eye shield over the eye immediately.

d. Consult ophthalmology.

e. Order a CT orbits.

\section{Appendix 3: Post-survey}

\section{MS3 Ophthalmology Post-survey}

Scale:

1-strongly disagree, 2-disagree, 3-neutral, 4-agree, 5strongly agree

1. Overall, do you feel this session helped improve your understanding of ophthalmology?

$1,2,3,4,5$.

2. Do you have a better understanding of ocular anatomy? $1,2,3,4,5$.

3. Do you feel more confident in performing an ocular history?

$1,2,3,4,5$.

4. Do you feel more confident in performing a basic eye exam?

$1,2,3,4,5$.

5. Do you feel that you have a better understanding of anterior segment diseases?

$1,2,3,4,5$.

6 . Do you feel that you have a better understanding of optic nerve diseases?

$1,2,3,4,5$.

7. Do you feel that you have a better understanding of retinal diseases?

$1,2,3,4,5$.

8. Do you feel that you have a better understanding of strabismus?

$1,2,3,4,5$.

9. Do you feel that you have a better understanding of basic lid lesions?

$1,2,3,4,5$.

10. Do you feel that this amount of time dedicated to this ophthalmology session was sufficient?

$1,2,3,4,5$.

11. Do you feel that more ophthalmology exposure would be helpful while you are in medical school?

$1,2,3,4,5$.

12. How effective was the instructor in teaching the material?

$1,2,3,4,5$. 
Please provide any critique on this session. What did you like the most about it? Any suggestions you have to make this better?

\section{Appendix 4: Quiz}

\section{MS3 Ophthalmology Quiz}

1. What experience have you had in ophthalmology? (Select all that apply.)

a. I participated in an elective in Phase I or Phase II.

b. I had an ophthalmology preceptor.

c. During OPC, I participated in a 6-hour didactic session on ophthalmology.

d. Other: please specify.

2. You are planning on doing a retrobulbar block on your cataract patient under sedation. The patient subsequently becomes apneic. What was the most likely complication?
a. Retrobulbar hemorrhage.
b. Loss of vision.
c. Intrathecal block.
d. Oculocardiac reflex.
e. Intravitreal penetration.

3. A 25-year-old woman with a past medical history of severe asthma controlled by albuterol nebulizers and long-term oral steroids presents with blurry vision in both eyes. On examination, her best corrected vision is $20 / 100$ in both eyes. Tension by tonopen is 15 in both eyes. Her pupils are normal. On slit lamp examination, you notice bilateral cataracts. What is the most likely cause for her cataracts?
a. Senile.
b. Steroid use.
c. Asthma.
d. Albuterol.
e. Congenital.

4. A 30-year-old man with history of HSV keratitis presents with an acute onset of blurry vision, foreign body sensation, and photophobia. On slit lamp examination, you notice the presence of a dendrite on his right cornea. What is the most appropriate treatment?
a. Acyclovir.
b. Prednisone.
c. Intravitreal injection of ganciclovir.
d. Observation.
e. Erythromycin ointment.

5. A 50-year-old woman presents to the emergency department with acute loss of vision and pain in her left eye. She has a headache and had an episode of emesis. On evaluation, her vision is 20/20 in the right eye and 20/200 in the left eye. Her tension by tonopen is 15 in the right eye and 45 in the left eye. On slit lamp examination, the right eye is normal, but the left eye has conjunctival injection, mid dilated pupil, and a shallow anterior chamber. What is the appropriate treatment?
a. Topical $\beta$-blocker.
b. Acetazolamide.
c. Mannitol.
d. Anterior chamber paracentesis.
e. $A, B$, and $C$.

6. A 20-year-old man has a new bump on his left upper eyelid that has been present for 2 weeks. He has some tenderness over the bump and it has been getting larger despite doing warm compresses and TobraDex ointment. Your exam indicates a chalazion. What is the most appropriate next step?
a. Tobramycin-dexamethasone ointment.
b. Erythromycin ointment.
c. Topical polymyxin B sulfate-trimethoprim.
d. Lid scrubs.
e. Incision and drainage.

7. A 30-year-old woman presents to the emergency department with acute onset of diplopia. She describes her diplopia as both vertical and horizontal splitting of images. When she covers one eye, her diplopia resolves. She also notices that her right eyelid has become droopier. On examination, her visual acuity is 20/20 in both eyes and tension by tonopen is 15 in both eyes. Her right pupil is $6 \mathrm{~mm}$ and constricts to $5 \mathrm{~mm}$. The left pupil is $3 \mathrm{~mm}$ and constricts to $2 \mathrm{~mm}$. On alignment, you notice a right exotropia and hypotropia. She has limitation of her right eye on adduction, elevation, and depression. What is your next step?

a. Measure the amount of deviation with prisms.

b. Plan for strabismus surgery.

c. Order a CTA looking for a posterior communication artery aneurysm.

d. Order a CTA looking for a vertebral artery aneurism.

e. Observation. 